\title{
PROFIL SURJA HUBUNG KARENA PROSES ENERGIZED (PEMBERIAN TENAGA) PADA SALURAN TRANSMISI $500 \mathrm{KV}$
}

\author{
Yuniarto \\ Program Studi Diploma III Teknik Elektro \\ Fakultas Teknik Universitas Diponegoro
}

\begin{abstract}
Yuniarto, in this paper explain that transient over voltage that happened because switching surge have to be paid attention to don't cause the damage equipments of insulation coordination system. This research aim to perceive the transient over voltage at the end of $500 \mathrm{kv}$ transmission line caused energized process by using EMTP (Electromagnetic Transients Program) as toll to simulate the energized process. Data for this research was taken from $500 \mathrm{kv}$ transmission line Ungaran-Pedan. From this research was expected can become a reference for power company in planning insulation coordination at transmission line.

Result of research show that transient over voltage at the end of $500 \mathrm{kv}$ transmission line caused energized process reach more or less twice its nominal voltage
\end{abstract}

Key word : energized, karateristik, transient over voltage, EMTP

\section{PENDAHULUAN}

Dewasa ini peningkatan peningkatan level tegangan saluran transmisi telah mencapai tegangan ekstra tinggi yaitu $500 \mathrm{kV}$.

Pemilihan level tegangan transmisi $500 \mathrm{kV}$ didasarkan pada pertimbangan bahwa transmisi 500 $\mathrm{kV}$ memiliki kemampuan menyalurkan daya listrik kira-kira 11 kali kapasitas transmisi $150 \mathrm{kV}$, untuk jenis penghantar yang sama dan jaringan yang digunakan lebih sedikit serta mempunyai kemampuan menyalurkan daya listrik yang lebih jauh.

Pemakaian tegangan saluran transmisi yang tinggi, mengakibatkan tegangan lebih transien yang dialami oleh saluran transmisi tersebut akan semakin tinggi juga. Tegangan lebih tersebut bisa merusak peralatan isolasi jika magnitude tegangannya melebihi BIL (Basic Insulation Level) peralatan isolasi yang dipakai. Tegangan lebih transien adalah tegangan yang mempuyai amplitudo sangat besar dan berlangsung sangat singkat yang disebabkan karena sambaran petir atau karena operasi pensaklaran.

Tegangan lebih transient yang disebabkan karena sambaran petir disebut surja petir sedang tegangan lebih transient yang disebabkan oleh operasi pensaklaran disebut surja hubung. Surja hubung salah satunya disebabkan oleh proses pemberian tenaga (energized), yaitu proses mengaliri sebuah saluran transmisi dalam keadaan tanpa beban dengan sumber tegangan, melalui operasi penutupan saklar.

Kenaikan tegangan yang terjadi karena surja hubung harus diperhatikan jangan sampai menyebabkan kerusakan koordinasi isolasi peralatan pada sistem.

Penelitian yang dilakukan penulis ini bertujuan untuk mengetahui profil dan karakteristik tegangan lebih transien yang terjadi karena proses energized, dengan memakai program simulasi EMTP (Electromagnetic Transients Program). Untuk obyek penelitian ini diambil data dari saluran transmisi 500 $\mathrm{kV}$ Ungaran-Pedan.

Hasil penelitian diharapkan bisa menjadi bahan masukan bagi perusahaan-perusahaan kelistrikan dalam menentukan koordinasi isolasi saluran transmisi.

\section{Analisis Transien : Gelombang Berjalan}

Gejala tegangan lebih transien pada saluran transmisi dapat diselesaikan dengan membuat rangkaian ekivalen satu fase, sehingga tiga fase saluran transmisi diasumsikan sebagai satu fasa tunggal. Studi tentang surja hubung pada saluran transmisi adalah sangat kompleks, sehingga pada penelitian ini hanya mempelajari kasus suatu saluran yang tanpa rugi-rugi. Suatu saluran tanpa rugi-rugi adalah representasi yang baik dari saluran-saluran frekuensi tinggi di mana $\omega \mathrm{L}$ dan $\omega \mathrm{C}$ menjadi sangat besar dibandingkan dengan $\mathrm{R}$ dan $\mathrm{G}$. Pendekatan yang dipilih untuk persoalan ini sama seperti yang telah digunakan untuk menurunkan hubunganhubungan tegangan dan arus dalam keadaan steady state untuk yang saluran panjang dengan konstantakonstanta yang tersebar merata.

Tegangan $\mathrm{V}$ dan I adalah fungsi-fungsi $\mathrm{x}$ dan $\mathrm{t}$ bersama-sama, sehingga kita perlu menggunakan turunan sebagian. Persamaan jatuh tegangan seri di sepanjang elemen saluran adalah

$$
\frac{\partial V}{\partial x} \Delta x=\left(R i+L \frac{\partial i}{\partial t}\right) \Delta x
$$

demikian pula halnya :

$$
\frac{\partial V}{\partial x} \Delta x=\left(G v+C \frac{\partial V}{\partial t}\right) \Delta x
$$


Persamaan dan tersebut di atas dapat dibagi dengan $\Delta \mathrm{x}$, dan karena hanya membahas suatu saluran tanpa rugi-rugi, maka $\mathrm{R}$ dan $\mathrm{G}$ akan sama dengan nol sehingga didapatkan :

$$
\frac{\partial V}{\partial x}=L \frac{\partial i}{\partial t}
$$

dan

$$
\frac{\partial i}{\partial x}=C \frac{\partial V}{\partial t}
$$

Sekarang variabel i dapat dihilangkan dengan menghitung turunan sebagian kedua suku dalam persamaan (3) terhadap x dan turunan sebagian kedua suku dalam persamaan (4) terhadap t. Prosedur ini menghasilkan $\partial^{2} i / \partial x \partial t$ pada kedua persamaan yang dihasilkan, dan dengan mengeliminir turunan sebagian kedua dari variabel i dari kedua persamaan tersebut, didapatkan :

$$
\frac{1}{L C} \cdot \frac{\partial^{2} V}{\partial x^{2}}=\frac{\partial^{2} V}{\partial t^{2}}
$$

Persamaan (5) ini adalah yang dinamakan persamaan gelombang berjalan suatu saluran tanpa rugi-rugi. Penyelesaian persamaan ini adalah fungsi dari (x-vt), dan tegangannya dinyatakan dengan :

$$
\mathrm{V}=\mathrm{f}_{1}(\mathrm{x}-\mathrm{vt})+\mathrm{f}_{2}(\mathrm{x}+\mathrm{vt})
$$

Yang merupakan suatu penyelesaian untuk terjadinya komponen-komponen ke depan dan ke belakang sebuah gelombang berjalan secara bersamaan pada sebuah saluran tanpa rugi-rugi. Variabel $v$ yang menyatakan kecepatan gelombang berjalan dapat dinyatakan dengan :

$$
v=\frac{1}{\sqrt{L C}}
$$

dengan :

$$
\begin{aligned}
& \mathrm{v}=\text { kecepatan rambat gelombang }(\mathrm{m} / \mathrm{s}) \\
& \mathrm{L}=\text { induktansi saluran }(\mathrm{H} / \mathrm{m}) \\
& \mathrm{C}=\text { kapasitansi saluran }(\mathrm{F} / \mathrm{m})
\end{aligned}
$$

Jika gelombang yang berjalan ke depan, yang disebut juga dengan gelombang datang, dinyatakan dengan :

$$
\mathrm{V}^{+}=\mathrm{f}_{1}(\mathrm{x}-\mathrm{vt})
$$

Maka gelombang arus akan ditimbulkan oleh muatan-muatan yang bergerak dapat dinyatakan dengan :

$$
\mathrm{i}^{+}=\frac{1}{\sqrt{L C}} f_{1}(x-v t)
$$

dari persamaan (8) dan persamaan (9) didapatkan bahwa :

$$
\frac{V^{+}}{i^{+}}=\sqrt{\frac{L}{C}}
$$

Perbandingan antara $\mathrm{V}$ dan i dinamakan impedansi karakteristik atau impedansi surja $\left(\mathrm{Z}_{\mathrm{C}}\right)$ dari saluran tanpa rugi-rugi.
Pada saat suatu tegangan $v(t)$ diterapkan pada salah satu ujung saluran transmisi tanpa rugi-rugi, maka unit kapasitasi $\mathrm{C}$ pertama dimuati pada tegangan $\mathrm{v}(\mathrm{t})$. Kapasitansi ini kemudian meluah kedalam unit kapasitansi berikutnya melalui induktansi L. proses bermuatan-peluahan (chargedischarge) ini berlanjut hingga ujung saluran dan energi gelombang dialihkan dari bentuk elektronik (dalam kapasitansi) ke bentuk magnetik (dalam induktansi). Jadi, gelombang teganan bergerak maju secara gradual ke ujung saluran dengan menimbulkan gelombang arus ekivalen juga. Propagasi gelombang tegangan dan arus ini disebut gelombang berjalan (travelling wave) dan gelombang ini kelihatan seolaholah tegangan dan arus berjalan sepanjang saluran dengan kecepatan yang diberikan oleh persamaan (7).

Saat gelombang yang berjalan pada suatu saluran transmisi mencapai titik transisi, seperti suatu rangkaian terbuka, rangkaian hubungan singkat, suatu sambungan dengan saluran lain atau kabel, belitan mesin, dan lain-lain, maka pada titik itu terjadi perubahan parameter saluran. Akibatnya sebagaian dari gelombang berjalan bergerak melewati bagian lain dari rangkaian. Pada titik transisi, tegangan atau arus dapat berharga nol sampai dua kali harga semula tergantung pada karakteristik teminalnya. Gelombang berjalan asal (impinging wave) disebut gelombang datang (incident wave) dan dua macam gelombang lain yang muncul pada titik transmisi disebut dengan gelombang pantul (reflected wave) dan gelombang maju (transmitted wave).

\section{Analisis Transien : Gelombang Pantul.}

Di sub bab ini akan dibahas tentang apa yang akan terjadi jika suatu tegangan dihubungkan pada ujung pengirim suatu saluran transmisi yang ditutup dengan suatu impedansi $Z_{R}$

Pada saat saklar ditutup dan suatu tegangan terhubung pda suatu saluran, maka suatu gelombang tegangan $\mathrm{V}^{+}$mulai berjalan sepanjang saluran dikikuti oleh suatu gelombang arus $\mathrm{i}^{+}$. Perbandingan antara $V_{R}$ dan $i_{R}$ di ujung saluran pada setiap saat harus sama dengan resistansi penutup $Z_{R}$. Oleh karena itu kedatangan $\mathrm{V}^{+}$dan $\mathrm{i}^{+}$di ujung penerima di mana nilai-nilainya adalah $\mathrm{V}_{\mathrm{R}}{ }^{+}$dan $\mathrm{i}_{\mathrm{R}}{ }^{+}$harus menimbulkan gelombang-gelombang yang berjalan ke belakang atau gelombang-gelombang pantulan $\mathrm{V}^{-}$dan $\mathrm{i}^{-}$yang nilai-nilainya di ujung adalah $\mathrm{V}_{\mathrm{R}}{ }^{-}$dan $\mathrm{i}_{\mathrm{R}}{ }^{-}$sedemikian sehingga,

$$
\frac{V_{R}}{i_{R}}=\frac{V_{R}^{+}+V_{R}^{-}}{i_{R}^{+}+i_{R}^{-}}
$$

dengan $\mathrm{V}_{\mathrm{R}}{ }^{-}$dan $\mathrm{i}_{\mathrm{R}}{ }^{-}$adalah gelombang-gelombang $\mathrm{V}^{-}$ dan $\mathrm{i}^{-}$yang diukur pada ujung penerima.

$$
\text { Jika dibuat } \mathrm{Z}_{\mathrm{C}}=\sqrt{L / C} \text { didapat dari }
$$
persamaan (10) : 


$$
i_{R}^{+}=\frac{V_{R}^{+}}{Z_{c}}
$$

dan

$$
i_{R}^{-}=-\frac{V_{R}^{-}}{Z_{c}}
$$

Kemudian dengan memasukkan nilai iR+ dan iR- ke dalam persamaan (11) dihasilkan persamaan :

$$
V_{R}^{-}=\frac{Z_{R}-Z_{C}}{Z_{R}+Z_{C}} \cdot V_{R}^{+}
$$

Koefisien pantulan $\rho_{R}$ untuk tegangan pada ujung penerima saluran didefnisikan sebagai $\mathrm{V}_{\mathrm{R}}{ }^{-} / \mathrm{V}_{\mathrm{R}}{ }^{+}$, jadi :

$$
\rho_{R}=\frac{Z_{R}-Z_{C}}{Z_{R}+Z_{C}}
$$

dengan :

$$
\begin{aligned}
\rho_{\mathrm{R}} & =\begin{array}{l}
\text { koefisien pantulan pada ujung } \\
\text { penerima }
\end{array} \\
\mathrm{Z}_{\mathrm{R}}= & \text { impedansi ujung penerima } \\
\mathrm{Z}_{\mathrm{C}}= & \begin{array}{l}
\text { impedansi karakteristik (impedansi } \\
\text { surja) }
\end{array}
\end{aligned}
$$

Pada saluran yang ditutup dengan impedansi karakteristik $\mathrm{Z}_{\mathrm{C}}$, terlihat bahwa koefisien pantulan untuk sama dengan nol, sehingga tidak ada gelombang pantulan, dan saluran berlaku seakan-akan panjangnya tidak terhingga.

Pada saat ujung saluran yang merupakan suatu rangkaian terbuka $Z_{R}$ adalah tak terhingga akan didapatkan harga $\rho_{R}$ sama dengan 1 (satu). Dengan demikan tegangan yang terjadi pada ujung penerima menjadi 2 kalinya tegangan pada sumber tegangan atau pada ujung pengirim.

Dari uraian di atas bisa disimpulkan bahwa besar tegangan lebih transien sangat tergantung pada impedansi karakteristik $\left(\mathrm{Z}_{\mathrm{C}}=\sqrt{L / C}\right)$, dimana impedansi karakteristik tersebut sangat berpengaruh terhadap koefisien pantulan $\rho_{R}$.

Harus diperhatikan di sini bahwa gelombanggelombang yang berjalan kembali ke arah ujung pengirim akan menyebabkan pantulan-pantulan baru yang ditentukan oleh koefisien pantulan pada ujung pengirim $\rho_{S}$ dan imedansi ujung pengirim $Z_{R}$.

$$
\rho_{s}=\frac{Z_{s}-Z_{C}}{Z_{s}+Z_{C}}
$$

dengan :

$$
\begin{aligned}
& \rho_{\mathrm{S}}=\text { koefisien pantlan pada ujung } \\
& \text { pengirim } \\
& Z_{R}=\text { impedansi ujung pengirim } \\
& \mathrm{Z}_{\mathrm{C}}=\text { impedansi karakteristik (impedansi } \\
& \text { surja) }
\end{aligned}
$$

\section{EMTP (Electromagnetic Transients Programs)}

EMTP (Electromagnetic Transients Program) adalah sebuah paket program komputer terintegasi yang secara khusus didesain untuk meyelesaikan permasalahan peralihan (transient) pada sistem tenaga listrik untuk rangkaian terkonsentrasi, rangkaian terdistribusi, atau kombinasi dari kedua rangakian tersebut.

Program ini pertama kali dikembangkan oleh H.M. Dommel di Munich Institute of Technology pada awal tahun 1960-an. EMTP sangat tepat jika digunakan untuk menganalisis transien pada operasi surja hubung (switching surge) atau surja petir (lightning surge) karena program ini secara khusus menyediakan fasilitas pemodelan untuk generator, circuit breaker, transformator, sumber surja petir dan pemodelan berbagai jenis saluran transmisi.

\section{METODE DAN PEMBAHASAN}

Perhitungan matematis dari rumus-rumus tersebut di atas akan sulit dan rumit sekali, sehingga untuk mempermudah dalam menganalisa dipakai EMTP sebagai alat bantu, dengan cara membuat simulasi rangkaian berdasarkan data-data yang diperoleh di lapangan. Sehingga metode penelitian ini dapat diuraikan dalam langkah-langkah kegiatan sebagai berikut :

- Pencarian data di lapangan.

- Pembuatan model saluran

- Penentuan nilai parameter saluran

- Penerapan model rangkaian ke dalam program EMTP

- Pengamatan hasil simulasi dari EMTP

Data-data untuk simulasi diambil dari saluran transmisi $500 \mathrm{kV}$ antara Ungaran-Pedan dengan asumsi sebagai berikut :

- saluran tersebut ideal

- pemutus tenaga membuka secara serentak

- pengamatan hanya dilakukan di ujung saluran.

- saluran transmisi dalam keadaan tanpa reaktor.

Berdasarkan data-data yang diperoleh maka didapatkan bentuk simulasi rangkaian sebagai berikut,

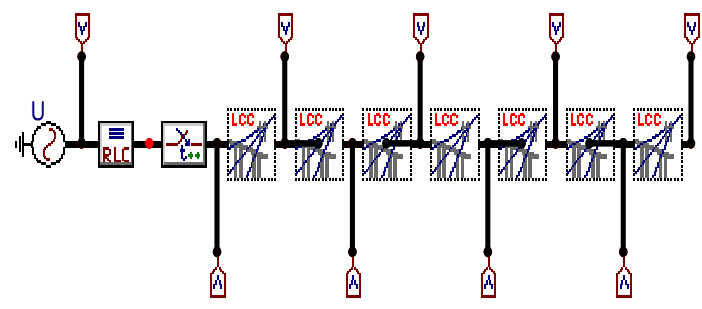

Gambar 1. Model Rangkaian untuk Simulasi

Simulasi dijalankan dengan skenario, saluran transmisi dalam keadaan tanpa beban kemudian saklar ditutup untuk memasukan tegangan sebesar 
408,25 kV. Dari hasil simulasi didapatkan profil dan karakteristik tegangan lebih transient yang terjadi di ujung penerima saluran transmisi $500 \mathrm{kV}$ Ungaran
Pedan karena proses energized di Gardu Induk 500 $\mathrm{Kv}$ Ungaran adalah sebagai-berikut.

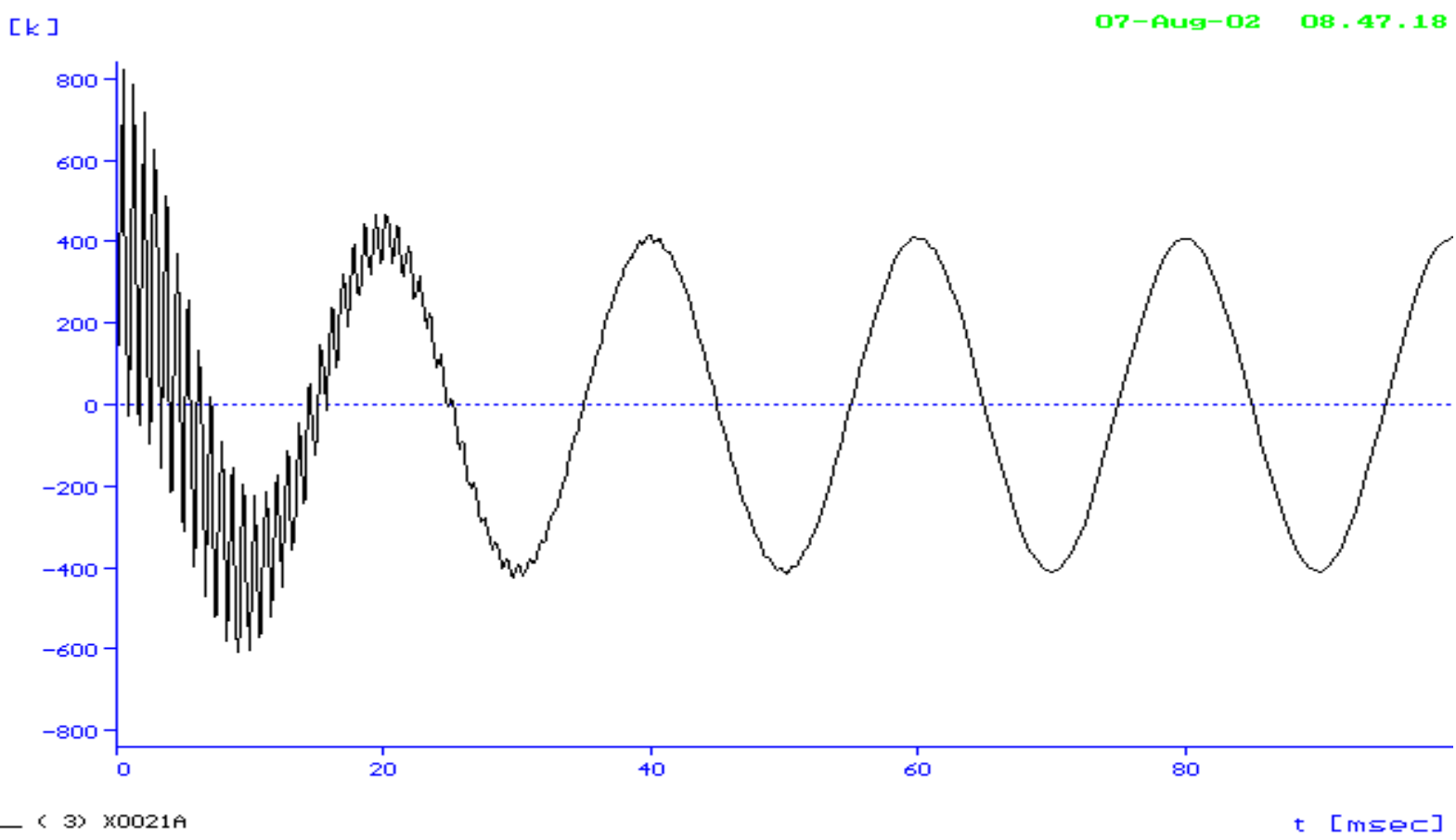

Gambar 2. Profil Surja Hubung di Ujung Saluran Transmisi 500 kV Ungaran-Pedan pada Saat Operasi Energized.

Hasil simulasi seperti yang tercantum pada gambar 2 di atas memperlihatkan bahwa magnitude tegangan lebih transien terbesar yang terjadi di ujung saluran selama proses energized pada saluran transmisi $500 \mathrm{kV}$ Ungaran-Pedan kurang lebih 800,20 kV. Tegangan tersebut hampir dua kali tegangan di ujung pengirim yaitu $408,25 \mathrm{kV}$.

Tegangan lebih transient tersebut berlangsung sangat cepat yang makin lama makin mengecil dan mencapai keadaan tunak (steady state) dalam waktu kurang lebih 30 mili detik.

\section{KESIMPULAN DAN SARAN \\ Kesimpulan}

Tegangan lebih transien yang terjadi di ujung penerima saluran transmisi $500 \mathrm{kV}$ yang terbuka pada saat proses energized mencapai dua kali tegangan yang dikenakan di ujung pengirim sehingga sangat berbahaya bagi koordinasi sistem osilasinya.

\section{Saran}

Untuk mendapatkan hasil simulasi yang lebih akurat perlu dilakukan lebih lanjut dengan menghilangkan asumsi-asumsi pada penelelitian ini. Juga perlu dilakukan penelitian lebih lanjut untuk menentukan langkah-langkah guna meredam tegangan lebih transien.

\section{DAFTAR PUSTAKA}

1. Arismunandar, A., 1994, Teknik Tegangan Tinggi, Pradnya Paramita, Jakarta.

2. Dommel, dan Herman, W., 1996, Electromagnetic Transients Program Vancouver, Canada.

3. EMTP Development Coordination group, 1998, The Electromagnetic Transients Program, Version 3,0 Rule Book 1, Volume 1, EPRI Report.

4. EMTP Development Coordination group, 1998, The Electromagnetic Transients Program, Version 3,0 Rule Book 2, Volume 1, EPRI Report.

5. EMTP Development Coordination group, 1998, The Electromagnetic Transients Program, Version 3,0 Rule Book 3, Volume 1, EPRI Report.

6. Galvan, A., and Cooroy, V., 1997, Analysis of Lightning-Induced Voltages in a Network of Conductors using the ATP-EMTP Program, Conference Publication no. 445, IEEE. 
7. Kundur, P., Morison, G.R., and Wang, L., 2000, Techniques for On-Line transient Stability Assessment and Control, Power Engineering Society Winter Meeting no.06, IEEE.

8. Marti, L., 1998, Calculation of Voltage profile Along Transmission Lines, IEEE on Transaction on Power Delivery.
9. Naidu, MS., V., Kamaraju, 1995, High Voltage Engineering, Tata MCGraw-Hill Publishing Company Limited.

10. T.S. Hutauruk, 1989, Gelombang Berjalan dan Proteksi Surja, Erlangga, Jakarta

11. Stevenson, W.D., Jr., 1996, Power System Analysis, International Edition Singapore. 